\title{
Application of Semantic Mining Technology in Building Intelligent Logistics System of Electronic Commerce
}

\author{
Xue Bai* and Juanjuan Liang \\ Department of Economic management \\ Guangdong Polytechnic \\ Foshan, China \\ chenxiaoyunld@163.com
}

\begin{abstract}
Keywords: Intelligent logistics system; B2B; Semantic mining; Distribution
\end{abstract}
\begin{abstract}
Electronic commerce logistics management information system is a network of people and computers, such as the information of the logistics related information collection, transmission, storage, processing, maintenance and use of the system. E-commerce logistics distribution is refers to enterprise logistics distribution using networked computer technology and modern hardware, software system and the advanced management method. The paper presents application of semantic mining technology in building intelligent logistics system of electronic commerce.
\end{abstract}

\section{Introduction}

Strengthen the research of the logistics process of e-commerce, and promote the business process reengineering of the electricity suppliers and logistics companies. Do not blindly in the existing process to promote the logistics information, or can not achieve efficient electricity suppliers logistics system. Process reengineering is to improve the efficiency of logistics system and reduce the waste by using the method of system to eliminate the ineffective logistics process.

E-commerce logistics distribution is refers to enterprise logistics distribution using networked computer technology and modern hardware, software system and the advanced management method, according to the needs of customers, according to the requirements of the user's order, a series of classification, coding, sorting, picking tally work, in accordance with the agreed time and place will determine the quantity and the specifications of the goods delivered to the user's activities and processes [1]. This new type of logistics distribution mode has brought about great changes in the field of circulation; more and more enterprises begin to take an active electronic commerce express, the use of e-commerce logistics distribution model.

The operation of electronic commerce itself is cross national boundaries. E-commerce for many enterprises to expand the boundaries of the market at the same time, but also to the logistics of enterprises put forward the requirements of globalization services. Logistics globalization will require that the organization of the logistics network, the logistics enterprises must set up logistics organization in the global scope, form a high-efficient logistics system of sensitive reaction, in unison, information communication, to cost as low as possible and the shortest possible time to global clients provide high-quality logistics services.

Electronic commerce logistics management information system (LMIS) is a network of people and computers, such as the information of the logistics related information collection, transmission, storage, processing, maintenance and use of the system [2]. Because the electronic commerce logistics is the organic combination of the information network and the traditional logistics, the logistics enterprise itself is a new way to the elements of the reorganization; therefore, e-commerce is not only a management system, but also a network, intelligent and social system.

E-commerce has a great influence on the development of logistics industry. Through the Internet, the logistics company to shippers customers is a greater range of take the initiative to find, able to expand business in the country and even the world, trading companies and factories can more quickly find the price the most suitable logistics company; e-logistics is committed to the world within the scope of the maximum number of a logistics needs of the owner of the business and 
provide logistics service of the logistics company are drawn together, neutrality and integrity, free online logistics market and help logistics supply and demand sides, conclude the transaction. At present, there are more and more customers through the online logistics market to find a customer, to find a partner, to find a foreign agent. In addition, e-commerce will be a business revolution, it broke the regional and national boundaries, has opened up a huge online business market, as a guarantee of the operation of e-commerce logistics will have a big development. The paper presents application of semantic mining technology in building intelligent logistics system of electronic commerce.

\section{Analysis of E-commerce Logistics Distribution}

Enterprise self logistics, the third party logistics has obvious superiority lies in its ability to focus on core business, improve core competitiveness, high efficiency of logistics enterprises, logistics is not the best for most enterprises, and the third party logistics enterprises can use their huge distribution network, professional logistics technology and business management, to improve the logistics efficiency, reduce the investment in fixed assets, enterprises need to invest huge funds for the transformation and construction of warehouse, purchase logistics infrastructure.

Data on the Web is different from that of the traditional database, and the data on the Web is more and more structured [3]. Data mining based on Web must be based on semi structured data and semi-structured data model. For the data in Web, it is the key to solve the problem that the data model is 1.5 . In addition to defining 1.5 structured data models, a semi-structured model extraction technique is also needed. We know that each site of the data are independently designed, and the data itself has a self narrative and dynamic variability, as is shown by equation (1), so the data mining oriented Web is a complex technology [4].

$$
(1-B)^{\delta}=\sum_{k=0}^{\infty}\left(\begin{array}{l}
\delta \\
k
\end{array}\right)(-1)^{k} B^{k}
$$

Distribution in the early stages of development, the development is not fast. In the era of electronic commerce, B2C logistics support is to rely on to provide, B2B logistics business will gradually outsourcing to the third party logistics, which is also the delivery mode of distribution system. No distribution, e-commerce logistics can not be achieved. 2, the distribution center as business flows, where information flows and logistics is centre. Information, socialization and modernization of the logistics distribution center to the three organically combined. Business and logistics are in operation under the command of the information flow.

Definition 1: The language description of the 1 semantic web: Semantic network: basic element | (Merge $<>$ basic element) basic element node $\langle>\langle>$ node semantic links $<$ node $>::=(<$ attribute value pair $>)<$ attribute value pairs $\rangle:\rangle=\langle$ property name $\rangle$ : $\langle$ attribute $\rangle$ ) $\langle$ semantic contact $\rangle$ : $\rangle$ $=(<$ system predefined semantic contact $><$ user defined semantic contact $\rangle)$.

Harth and Dexker proposed a multi index based on the storage of RDF data, the method to consider the data context. In $\{\mathrm{s}, \mathrm{P}, \mathrm{O}, \mathrm{c}\}$, form of the sixteen types of small access patterns, the establishment of six types of indexes will be covered, in which the $\mathrm{C}$ representative context. This model allows for quick retrieval of small pieces, and applies to s, P, O, C, either as a variable or a specific value. Therefore, this method is also located in a simple state based query, not suitable for more complex query processing.

Design pattern Partitions Value. The model is used to create a class and its subclasses, which are those of the class, and the class of the objects, and then create an object property associated with the class, which is functional and range is the class. The class is usually used to represent a class value. The class that is and the form that classes covered covering the being. If there are three classes of $\mathrm{A}$, $\mathrm{B}, \mathrm{C}, \mathrm{B}$ and $\mathrm{C}$ are the subclasses of $\mathrm{A}$. Now suppose we have a Axiom A that specifies the Covering to be covered by $\mathrm{B}$ and $\mathrm{C}$, which means that $\mathrm{A}$ members must be members of $\mathrm{C}$ and $\mathrm{B}$. If $\mathrm{B}$ and $\mathrm{C}$ don't intersect, then the A member must be a member of $\mathrm{C}$ or $\mathrm{B}$. $\mathrm{A}$ is not a member of the $\mathrm{C}$, which is not a member of the $\mathrm{B}$. In fact, $\mathrm{A}=\mathrm{B} \mathrm{C}$.

E-commerce is mainly to carry out the business of products wholesale business, so also known as the wholesale e-commerce. In fact, electronic commerce is not only refers to the network retail 
industry, but also the core of the market potential of a large number of enterprises in the retail industry. B2B e - business model is a way of integrating information exchange and transaction between the buyer and seller and service to their brokers (e.g., financial institution) [5]. And the use of this technology will fundamentally change the business plan, production, sales and operation mode, and even change the basic mode of production of the whole industrial society. Therefore, the e-commerce business model between the enterprises more and more attention, many people in the industry believe that the future development of e-commerce is an important direction.

$$
F S=\operatorname{abs}\left(\frac{M I_{F A}}{M I_{F A}+M I_{F B}}-0.5\right)
$$

One is that the information in the logistics system becomes the basis of the entire supply chain operation. Network is the platform, supply chain is the main body, and electronic commerce is a means of. Two is the enterprise's market competition will be more performance for the competition of the enterprise alliance represented by the internet [6]. Three is the advantage of the market competition will no longer be the enterprise has the material resources, but it can mobilize, coordination, and finally to integrate the number of social resources to enhance their market competitiveness. Four is the logistics system is facing the basic technical and economic problems, is how to effectively allocate information resources among the supply chain members to make the whole system of customer service level is the highest. The pursuit of the lowest total logistics costs while providing customers with personalized service.

Definition 2: RDF is based on the idea that Web identifiers (called Resource Identifiers URIs or Uniform) are used to identify objects, with a simple property (property) and attribute values. This allows the RDF to represent a simple statement of one or more of the resources as a graph (graph) consisting of nodes and arcs, where the nodes and arcs represent resources, attributes, or attributes.

Mobile electronic commerce is not restricted by time and space, the business people can collect a large amount of market information, and through the processing and processing of this information, it is easy to get the full value of timely business information and information, this information on the business management policy, product development and marketing has important value.

The knowledge of the traditional transaction database mining is usually single dimension (Single-Demension). For example, "people who buy a computer also buy Printers" such knowledge, which characterizes the "buy" behavior as the focal point (d) of the association of goods. However, in relational databases, only such knowledge may not be enough. For example, it may be possible to further wonder "what kind of people who buy a computer can also buy Printers more likely?", therefore, like the "high income people in the purchase of computers to buy Printers," the more need for such knowledge. Because the relational database can store the basic information of the customer and the customer purchase records, so that knowledge can be obtained [7].

Definition 3: According to the definition of RDF, the resource itself is the subject subject, the attribute name is the predicate predicate, the attribute refers to the object object. The description of network resources by the main predicate - object form, RDF itself represented as XML documents, such as those above, written in XML file is: <? XML version = "1.0"?.

Logistics is an important part of $\mathrm{E}$ - commerce. The relationship between e-commerce and logistics with "delivery, failure delivery" is no exaggeration to describe. It can be said that the electronic commerce is the guarantee of the information transmission, and the logistics is the guarantee of the execution. There is no logistics, electronic commerce can only is a blank check, and also the development of electronic commerce will have a positive impact on logistics.

\section{Building of Electronic Commerce Logistics Management Information System}

The characteristics of virtual property not only can help the decision making, but also support the decision maker to obtain the high efficient decision-making information support. Distribution elements of the digital, after the code, breaking the constraints of time and space, distribution business operators and customers can obtain information platform to obtain the appropriate distribution information, thereby reducing the information asymmetry between the parties to the maximum extent, effectively reducing the operational uncertainties and the link between the 
operational uncertainties, breaking the previous distribution on the road, to achieve full monitoring delivery".

For the development of e-commerce enterprises, the use of the third party logistics mode to solve the logistics problem has obvious strategic advantages, the main performance is: (L) make ecommerce enterprises can better focus on their core competitiveness. (2) The third party logistics provider can better carry out technological innovation according to the market, so that the service and the requirements of electronic commerce. (3) The use of the third party logistics mode to achieve the size distribution, saving the logistics costs of e-commerce enterprises. (4) The use of the third party logistics provider of professional logistics technology, shorten the delivery time, so as to improve the corporate image of e-commerce enterprises.

Definition 4: Resources, attributes and attribute values in RDF are represented by Subject, Predicate, Object, RDF, and the three tuple (Triple), which is composed of subject, predicate and object. If the subject and object are considered as nodes, attributes are considered as a side, then a simple RDF statement can be expressed as a RDF directed graph [8].

$$
X^{\prime}=W(X, P)=\left(\begin{array}{ccc}
a_{1} & a_{2} & d_{1} \\
a_{3} & a_{4} & d_{2} \\
0 & 0 & 1
\end{array}\right)\left(\begin{array}{l}
x \\
y \\
1
\end{array}\right)
$$

Most users in the evening of business activities only with the $\mathrm{B} 2 \mathrm{C}$ e-commerce related, but the maximum economic value of network technology is reflected in the business enterprise e-commerce. The traditional way of data exchange between enterprises is through electronic data interchange (EDI) approach. However, this technology is too complicated, and can only be understood by experts, programming and maintenance are very difficult, and error prone. Each of the data exchange between enterprises needs to be specialized programming, development costs. In addition, EDI is an isolated technology; the exchange of data can not be easily integrated with other commercial applications.

E-commerce logistics distribution is the ultimate goal in the most reasonable way, the fastest speed, the lowest cost to meet the customer's needs, so as to achieve e-commerce companies and customers "win-win" situation. According to the study of relevant literature, e-commerce logistics distribution has the following advantages: (1) to realize the efficient delivery of goods: the speed, scale and efficiency of the allocation of goods are greatly improved, which makes the efficient delivery of goods to be realized. (2) The timely control of the distribution system: the automatic procedure of the distribution system, the dynamic control of the distribution process, the instantaneous arrival of the instruction, and the timely control of the distribution, as is shown by equation (4).

$$
\begin{array}{r}
I_{\sigma}(i, j)=\sigma_{\Omega_{i j}}, \Omega_{i j}=\{(i-1) l+1 \leq x<i l, \\
(j-1) l+1 \leq y<j l\}
\end{array}
$$

Professional group for the logistics core competitiveness of the electricity suppliers are to enhance the direction of the. No matter what model, any one of the mature business enterprise in its own logistics strategy layout of the various stages, can not be separated from the participation of the third party logistics, which is also many well-known business enterprise and third party logistics companies closely cooperate, skilled use of logistics mode. Therefore, only to strengthen the hard power of the third party logistics, establish effective industry self regulatory mechanism, improve the practitioners literacy, strengthen supervision and guidance, promote the national policies and regulations related to the formulation and implementation, to expand exchanges and cooperation with foreign countries in the same industry, to achieve the standard of mutual recognition, in order to make China's third party logistics and the normalization, internationalization development path, the electricity supplier with together to achieve a win-win situation.

The purpose of semantic web is to allow more advanced knowledge management system, which can be used to organize knowledge according to the concept of meaning, and the automatic tool support knowledge maintenance of compatibility checking and new knowledge extraction. 
The end user of the system is a logistics enterprise. Modern logistics not only consider the issue of goods distribution from producer to consumer, but also consider the purchase of raw materials from suppliers to producers, as well as the transport, storage and information in the process of product manufacturing [9]. And with the development of e-commerce, e-commerce logistics will be information, automation, networking, and intelligent, flexible combination. Therefore, modern logistics is to meet the needs of consumers as the goal, the manufacturing, transportation, sales and other market conditions to consider a unified strategy. The characteristics of logistics enterprises are to use the logistics distribution management system to provide the auxiliary decision-making, as is shown by equation (5).

$$
f(b)-f(a)=\frac{f^{\prime}\left(x_{3}\right)}{\frac{1}{x_{3}}}(\ln b-\ln a)=x_{3} f^{\prime}\left(x_{3}\right) \ln \frac{b}{a}
$$

The way to solve this problem through the semantic web is not to develop a more advanced, but from the point of view of web pages. If you use a more appropriate language to replace the HTML, you can better express the content of the web pages you can write, this summary page not only can contain format information to generate a document that is easy for human reading, but also can contain other information describing the content. For example, in our case, we can include the following information: compared with the HTML, this expression is more likely to let the machine processing.

Definition 5: The conceptual model of RDF is a graph (graph). RDF provides a XML syntax called RDF/XML to write and exchange RDF diagrams. The RDF (triples) is different from that of $\mathrm{RDF} / \mathrm{XML}$, and is the RDF normative (Syntax), as is shown by equation (5). RDF/XML is defined in the RDF/XML syntax specification [RDF-SYNTAX]. This section describes the syntax of RDF/XML.

Change in concept, from "push" to "pull"'. Distribution center should be more consideration of the "customer to provide what services", from this sense, it is "Pull", rather than simply consider "I can provide customers with which services", that is, "Push". If some distribution centers in the beginning to provide the regional logistics services, to provide a long distance service, but also to provide more and more service projects. And as the distribution center sent to manufacturers of "stagnation", and it is direct delivery to customers. More and more manufacturers to all logistic work all commissioned Peihuo center to do, from the basic meaning, distribution center has been extended to production in the factory to the. How to meet the needs of customers in the hands of the goods is to the customer, and it is to see the distribution center of the operating level. Distribution center not only to maintain close partnership with the manufacturer, but also directly with customers, to understand customer needs and timely information, and communication between manufacturers and customers, plays a bridge role.

\section{Application of Semantic Mining Technology in Building Intelligent Logistics System of Electronic Commerce}

E - Commerce is a business tool in twenty-first Century, and modern logistics will become the fulcrum of the development of electronic commerce. In the era of electronic commerce, logistics and information flow are also becoming more and more important. Only the correct and effective use of modern logistics technology in the electronic commerce logistics management can be a good solution to the electronic commerce logistics, many problems, so that e-commerce logistics to better serve e-commerce activities, but also to better and faster development of e-commerce.

Definition 6: software may be required to handle some of the RDF data, which contains the data types that are not handled by the software, so that some of the software is unable to do so. One reason is that, in addition to - rdf:XMLLiteral, the RDF itself can not define the type of URIref. Therefore, unless the RDF software understands a particular URIref, it will not be able to determine whether a URIref is actually a data type. 


$$
\begin{gathered}
\bar{R}_{i}(k)=\frac{1}{k} \sum_{j=1}^{k} R_{i}(j)=\frac{1}{k}\left[\sum_{j=1}^{k-1} R_{i}(j)+R_{i}(k)\right] \\
=\frac{k-1}{k} \bar{R}_{i}(k-1)+\frac{1}{k} R_{i}(k)
\end{gathered}
$$

The traditional logistics distribution process is composed of many business processes, each business process depends on people to link up and coordination, which is difficult to avoid the impact of human factors, the problem of the discovery and fault processing will be delayed [10]. Ecommerce logistics distribution mode with the help of network system can realize the timely monitoring and timely decision-making, distribution information processing, delivery of goods, the problem of the search, the speed of instruction issued by the traditional logistics distribution can not be compared, distribution system automation procedures, distribution process of the dynamic control, the instantaneous arrival of the command can be achieved.

Definition 7: Data type properties (Property Datatype) - the Schema XML data type values or literal RDF, which can not be passed, symmetric, inverse functions. Attribute (Property Annotation) - to add information to classes and it is properties, individuals, and ontologies.

E-commerce logistics process including transportation, storage, loading and unloading, packaging, distribution processing and its associated logistics information processing. They are interrelated and constitute the functional elements of the logistics system. These five processes can be called as the starting point of electronic commerce, commodity packaging, electronic commerce, commodity transportation, electronic commerce center, commodity storage, electronic commerce, the loading and unloading of goods, the central nervous system of electronic commerce, logistics information.

E-commerce transaction process information flow, capital flow, commerce can well through electronic means of quickly. It greatly shortened the trading time, increase trade opportunities, improve the trade efficiency, convenient for the parties to the transaction, reduce transaction costs, reflected the advantages of electronic commerce. But to make the advantages of electronic commerce is fully reflected, it needs to have a well-developed logistics industry to match, must be in the entire process of production and operation, to ensure the smooth flow of logistics, efficient and low cost. In the era of electronic commerce, the requirements for logistics and the traditional business methods are significantly different, as is shown by figure 1.

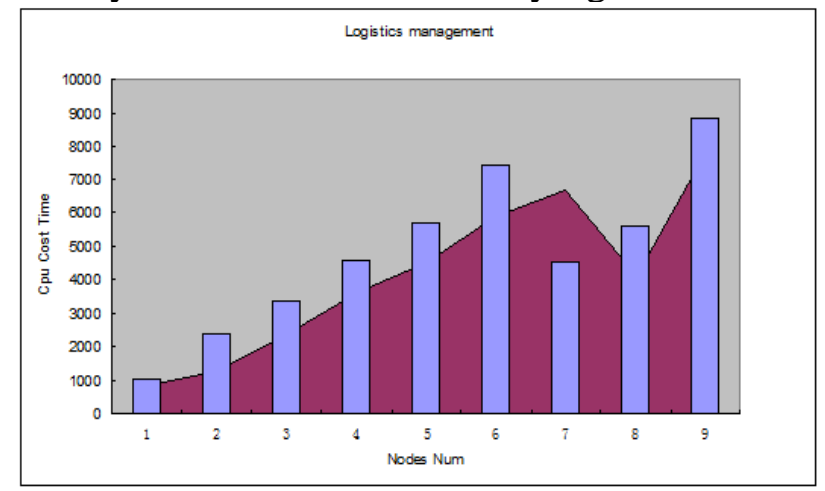

Figure1. Traditional logistics channels in the wholesalers and retailers and other intermediaries.

The socialization and industrialization of logistics and distribution system, the key is to establish suitable for the development of electronic commerce logistics center, set up logistics center are mainly self built, rebuilt, the construction and generation of building four, at present the enterprise uses generally LianJian and on behalf of two, but LianJian enterprises can with the original storage and transportation equipment, reducing logistics cost and investment, improve the distribution of benefits, on behalf of the construction of logistics center, also known as the third party logistics, is refers to the enterprise commissioned by the supplier or distribution center generation complete the operation mode of logistics services, business and concentrate on core business to obtain the conservation and efficient. 
Electronic commerce logistics technology refers to the electronic commerce logistics activities in the transfer and storage of goods, to provide the community with the technology of invisible services. According to the content, e-commerce logistics technology can be divided into physical and electronic commerce technology. Through of e-commerce technology in the logistics application and the operation mode of logistics is introduced, to understand the under the electronic commerce environment, commerce, capital flow, confidence in stream can through the network rapidly off-site achieve, logistics management has exceeded the traditional warehousing and distribution functions, presents many new characteristics and trend of development

\section{Summary}

E-commerce will promote the improvement of logistics infrastructure, logistics technology and logistics management level. The characteristics of high efficiency and global demand are for electronic commerce requires the improvement of logistics infrastructure, but also to improve the level of logistics technology to improve the efficiency of logistics. In addition, the level of logistics management directly determines the level of logistics efficiency, but also affects the realization of the high efficiency of e-commerce. Only by improving the management level of logistics, establishing scientific and reasonable management system, using scientific management means and methods in logistics management, we can ensure the smooth flow of logistics, realize the rationalization and efficiency of logistics, and promote the development of logistics in electronic commerce.

\section{Acknowledgment}

This paper is supported by 2014 Guangdong Province outstanding young teachers training program (Yq2014185).

\section{References}

[1] Haifei Zhang, "A Method of Mappings from Reconstructed Relational Databases to RDF Based on RDF View", JDCTA, Vol. 6, No. 12, pp. $11 \sim$ 19, 2012.

[2] Gayan Prasad Hettiarachchi, Dilhari Attygalle, Dhammika Suresh Hettiarachchi, Azusa Ebisuya, "A Generic Statistical Machine Learning and Data Mining Framework for Record Classification and Linkage", IJIIP, Vol. 4, No. 2, pp. 96 106, 2013.

[3] Ling Qiu, "An Approach Based on Instances Flow Analysis for Maintaining Consistency in Ontology Structure", IJACT, Vol. 5, No. 9, pp. $1141 \sim 1149,2013$.

[4] Hongxin Wan, Yun Peng, "Clustering and Evaluation on Electronic Commerce Customers Based on Fuzzy Set", IJACT, Vol. 5, No. 3, pp. 199 206, 2013.

[5] Feng-Jing Shao, Shun-Yao Wu, Jin-Long Wang, Chun-Yuan Tian, "Automatic Theme Extraction for Marine Data Marts Using Semantic Web", JCIT, Vol. 8, No. 1, pp. $765 \sim 771$, 2013.

[6] ZHANG Xudong, "The Research on the Electronic Commerce of Independent Trust System in China", JCIT, Vol. 8, No. 7, pp. $113 \sim$ 121, 2013.

[7] Jie Wu, Dong Wang, Huanye Sheng, "RISE-IS: A Semantic Bridge Between EPC Network and RDF-based EPCIS Accessing Applications", JDCTA, Vol. 5, No. 6, pp. 155 162, 2011.

[8] Yi Wang, JieHong Luo, "Ontology learning and mapping in semantic web based on formal concept analysis technology", JCIT, Vol. 7, No. 10, pp. $381 \sim 388,2012$.

[9] Ling Liu, Zijiang Yang, "Improving Online Shopping Experience using Data Mining and Statistical Techniques", JCIT, Vol. 8, No. 6, pp. $466 \sim$ 474, 2013.

[10] Wang Qifeng, Zhou Liandong, Lv Hongbo, "Knowledge Management Approach for Manufacturing Process Based on Semantic Web", JDCTA, Vol. 5, No. 10, pp. 127 135, 2011. 